\title{
Stylistic Performance through Affective Marking: A Case of Multilingual Literary Discourse
}

\author{
Urjani Chakravarty \\ Department of Communication, IIM Indore University, India \\ E-mail: urjanic@iimidr.ac.in
}

Doi:10.7575/aiac.alls.v.7n.6p.157

Received: 18/08/2016

URL: http://dx.doi.org/10.7575/aiac.alls.v.7n.6p.157

Accepted: 29/10/2016

\begin{abstract}
This paper provides an overall analysis of how multi-lingual writer like Amitav Ghosh write about emotion in his literary text, and emphasize on how multilingual authors display emotion/affect through use of literary multilingualism (affective markers) combined with writer style. Through use of multiple strategies, they reduces the limitations of interpretation of their texts. Furthermore, this paper highlighted the centrally sociolinguistic and cognitive dimensions of the relationships between multilingualism and emotion and how this is influenced by assumptions of Relevance Theory i.e. optimal relevance in a literary text. One should expect to find relationships between sociolinguistic diversity and affective expression for most authors in locally specific ways, whether multilingual or not. Such scholarship can then illuminate how the authors by using literary multilingualism through writer style and affective markers can shape emotions across various contexts in a literary text. Future research into multilingualism and emotion should continue to distinguish between how multilingual authors use linguistic forms to show feeling, and how they express about feeling in their created texts.
\end{abstract}

Keywords: Language, Culture, Literary Multilingualism, Style, Affect and Relevance Theory

\section{Introduction}

The reflection of culture through language as depicted in texts composed in multiple languages undoubtedly plays a crucial role to make possible a body of literature to be broadly recognized as world literature. This paper discusses one such culture through language manifestation - literary multilingualism. The attempt is to draw association between use of multi-lingual words (style) and deployment of emotion (affect) in selected Diasporic literary texts, The Hungry Tide (THT) and Sea of Poppies (SOP) written by Amitav Ghosh, in order to establish that multilingual words help express culture specific emotion and contribute to the understanding of the text within the framework of Relevance Theory.

The questions often raised within multi-lingual scholarship can be expressed as:

Does a multilingual author feel like a different person when writing in different languages? What are these differences? (Pavlenko, 2006, p. 84).

The present study addresses these questions as well as discusses how a Diasporic author in his novels produce affect for the readers. To explore a multilingual writer's affective displays in his different languages one must first study the various aspects of the written expression that creates affect for the reader. The present work investigates how the author implicitly communicates his affective stances through Hindi and Bengali indexical strategies. As defined 'affect' encompasses emotions, attitudes and feelings which are mapped through markers/codes such as address terms as well as metaphors, the use of these markers/ codes imply a character's emotional response for the narrated events by the author. The focus is on writer's style in literary discourse and also establishing that passages depicting affective markers are actually writer's style, rich in emotional language, including such features as interspersing, interjections and repetition.

The work contends that an author uses particular multilingual words or 'affective markers' in order to give the reader a cue to an emotional state and further, that this observable fact is influenced by the author's cognitive need to gain optimal relevance. 'Affective markers' can be defined as the multilingual words phrases that facilitate the representation and interpretation of an emotional state in a literary text. The creation of these markers by the author can be corroborated by Kachru's investigations on 'bilingual creativity' wherein he writes,

[I]n contact literature, the bilingual's creativity introduces a nativized thought-process (e.g., Sanskritic, Yoruba, Malaysian) which does not conform to the recognized canons of discourse types, text design, stylistic conventions and traditional thematic range of the English language, as viewed from the major Judaic-Christian traditions of literary and linguistic creativity (1986, p. 160). 
options involving a range of affective markers, is ever present in the writings of multilingual authors from India, who have facility in two or more languages, and also that this is manifested through literary multilingualism of Indian languages within the English language construction. An author's style in a literary text can be viewed as having been determined by a series of options that the text manifests and which are selected from a given range of possibilities, which the language offers for creating a particular affect. Some of the questions that this study will try to answer include: What is the function and purpose of these affective markers? In what context are these markers being used?

As a result, one must comprehend how and in what way (style) authors are incorporating the words from Indian languages in their English constructions to give an ostensive stimulus to the reader in order to create (make) a particular affect.

\section{Background: Amitav Ghosh as Diasporic Writer}

Diasporic writers such as Amitav Ghosh as multi-linguals exploit their facility with several languages to enrich their creative output. Amitav Ghosh is one of India's one of the most renowned writers. The present study has taken up two of his novels namely, The Hungry Tide and Sea of Poppies. The Hungry Tide is thematically based on the nature novel genre and has its background set in the Sunderbans, as described by the author in the local language as bhatir desh or a tide country. Through his characters Nirmal, Kusum and Horen, and later Piya, Fokir and Kanai, the author foregrounds human bonding, which transcend language, class and gender.

The colonial period was marked by migration of large number of people from one part of the globe to the other which led to the changed demographic constitution of several countries giving rise to new intercultural identities and communities. An example of this is the contact of the British colonizers with the indigenous population of India resulting in the growth of a hybrid culture, which in turn gave rise to a hybrid language comprising various pidgins, creoles and colloquialisms. This is aptly illustrated in Ghosh's novel Sea of Poppies, a historical fiction portraying characters from all classes and regions during the colonial period in India. It revolves around a former slave ship, the Ibis. It is a carrier ship having opium and indentured slaves to be sold in China and Mauritius Islands respectively. The places are far away over the "Black Waters" of the Indian Ocean. As the Ibis is outfitted for the voyage, one is led through the magnificently exhilarating cosmos of $19^{\text {th }}$ century Kolkata, the bustling port city, which becomes the site of forbidden romance and drama having serious depiction of sati practice. The ship's crew and passengers include opium factory workers, American sailors, a free spirited French orphan, lascars, coolies, convicts, rajas and sahibs and it reflects Kolkata's cosmopolitan racial and socioeconomic eddy. The portrayed world is a polyglot one, ringing with pidgin, Chinglish, Hinglish, the inimitable slang of seafarers and dialects of the Indian subcontinent. It is the beginning of a journey into the unknown as they leave the shores of Hooghly River and into the vastness of the sea, their old familiar ties are broken, and they form new relations called as "jahaj-bhais, or ship-brothers", who will further transform themselves as "girmityas" with new livelihoods as well as identities. The author meticulously recreates the glories of that time with help of variations in language structure and lexicon.

\section{Background: Multilingualism, Style and Affect}

Affect as discussed in this study is something that is produced not by using expressions of emotions, rather, it refers to as an element of stance taking in literary discourse and as language used during interaction between the writer and the reader. Affect is defined as the ways in which writers express their own or describe someone else's emotional attitude through language. Further, affect can be described on the basis of "aspects of emotion, feeling, mood or attitude, which condition behavior" (qtd. in Arnold, 2011). The other possible view on 'affect' by Stevick propounds the following interpretation:

One's 'affect' towards a particular thing or action or situation or experience is how that thing or that action or that situation or that experience fits in with one's needs or purposes, and its resulting effect on one's emotions ... affect is a term that refers to the purposive and emotional sides of a person's reactions to what is going on. $(1999, \mathrm{p} .55)$

The discussion follows Niko Besnier (1990) as he states affect to be associated with interpersonal interaction, context, rituals or social stratifications. Besnier conducted an extensive anthropological study of affect and language and described emotive words, connotative sense of words and other cross-linguistic occurrence of affect. He further classified his list of affect inducing categories into terms of address, honorifics, expletives, exclamations, reduplication, intensifiers, onomatopoeia and word order, etc.

Furthermore, to better understand use of affective markers by any author one must also consider or understand writing style as an important condition. Studies on the subject define writing style as the manner in which a writer chooses from among different options to address a reader. Crystal defines style in the following manner,

Style is seen as the (conscious or unconscious) selection of a set of linguistic features from all the possibilities in a language. (2007.Web)

This reflects not only the writer's personality, but it also shows how s/he perceives the reader while writing a novel. Style reveals the choices that the writer makes in lexical and syntactical structures, and figures of thought.

\section{Theoretical Framework: Discussion on Relevance Theory}

Relevance Theory has long been considered as an apt tool for analysing human communication and cognition as developed by Dan Sperber and Deirdre Wilson (2002, p. 249) and has its applications in various domains.

According to Sperber and Wilson (2002) the concept of "relevance" is the requirement of a piece of information either 
within a context or for an individual at a particular time. Communication, the theorists both creates and uses the definite expectation of relevance. They further state that Inferential Communication entails affect created for the audience and shows the intention of doing the same.

Communicative Principle of Relevance states that each act of communication conveys the presumption that the speaker has chosen the most relevant utterance in consideration of her abilities and preferences and that the hearer automatically expects the utterance to be sufficiently relevant to be worth putting in some effort to process it. Ostensive-Inferential Communication (Relevance Theory's term for Inferential Communication) comprises two layers of intentions:

Ostensive-Inferential Communication $=$ The Informative Intention (the intention to inform an audience of something) \& The Communicative Intention (the intention to inform the audience of one's informative intention) Concept of Optimal Relevance (Sperber and Wilson, p. 257)

An ostensive stimulus is optimally relevant to an audience if and only if:

a. It is relevant enough to be worth the audience's processing effort;

b. It is the most relevant one compatible with communicator's abilities and preferences.

The Relevance Theorists consider the Communicative Principle of Relevance (Sperber and Wilson, 256) and the notion of optimal relevance as the key to relevance-theoretic pragmatics. It is the principle that operates in the domain of literary discourse if one accepts the latter as a form of communication taking place between an author and his reader.

The theorists design their notion of optimal relevance on how the audience in an act of ostensive inferential communication base the interpretation on interaction between effort and effect. For this purpose a model has been created with the help of the assumptions of Relevance Theory:

Ostensive Inferential Communication $(\mathrm{OIC})=>$ Literary Discourse $=$ Informative Intention (type of style adopted in writing) \& Communicative Intention (intended emotional affect) \& Ostensive Stimulus (affective markers).

Therefore this work ground itself on Relevance Theory and explains the socio-cognitive motivations behind the affective meanings of the usage of affective markers as they are found in specific instances of the written text. To substantiate this point studies have shown how use of markers with their various positional occurrences, inherently express affect. Du Bois, Englebretson, Keisanen have shown how certain markers, grammatical forms or linguistic practices are functionally used to express a speaker's affective stance in discourse (qtd. in Haddington, et al. p. 75-6). Thus, the author by interspersing words of Hindi/Bengali etc. in English construction, whose individual formal structures do not inherently have an affective meaning, but which based on the analyses belongs to the class of affective markers, gives an ostensive stimulus to the reader in order to create a particular affect.

\section{Analysis of Style and Affect}

Ghosh's affective stance in the literary texts engage more than one language. The analysis is based on four types of writer styles namely narrator style, interlocutory style, character style and mixed style which are modelled on Michele Koven's speaker roles (qtd. in Pavlenko 2006, p. 93). Rather than compare the functions of individual indexical devices in the two languages, the study compares the larger writer style perspectives that such devices help to instantiate. In this way, the combinations of writer style perspectives present in narratives told in the languages used by the author, and the affect that is intended (by him) for his readers is investigated.

1. Narrator style: Narration in literary discourse is through characters or direct narration of past and present events. The multilingual words or phrases used in the text thus generate the narrative style. Examples of the narrator style are the following extracts from the novels:

1.1) Amitav Ghosh uses the narrator style and his affective marker is the use of the word achol as a simile to explain the position and description of the Sunderbans.

The islands are the trailing threads of India's fabric, the ragged fringe of her

sari, the āchol that follows her, half wetted by the sea....(THT,p. 7).

Sunderbans act as the backdrop of Ghosh's novel and with the help of this simile, the author hints at both social and natural harsh conditions present in the islands. Further, in order to explain his usage of the metaphor in The Hungry Tide the author gives a detailed description of the locale, which acts as the ostensive stimulus for the reader to process his intention.

In case of Sea of Poppies, the example of narrator style is a couplet in Bhojpuri sung by the girmityas (workers migrating to foreign lands for menial labor) when the ship Ibis is leaving the shore of Bengal.

Talwa jharáilé

Kãwal kumhláile

Hansé royé

Birahá biyog 
The pond is dry

The lotus withered

The swan weeps

For its absent love

Kaisé katé ab

Birahá ki ratiyā

How will it pass

This night of parting (SOP, p. 398)?

In the above example the narrator style is presented through two song lines, which is different from the other authors, and Ghosh's other novel that has been taken up for study here. The song describes the fear of the unknown in a bride who is leaving her home after her marriage. The women of the household sing to the bride as a part of the wedding ceremony at the time of her journey to her husband's house. The authors who used narrator style intend to evoke the reads interest and guide the reader to process the text that he has created and with help of these affective markers convey their information.

2) Character style: Character style is use of voice of particular characters to replay the thoughts, feelings, words, deeds narrated in an event through various modes of speech in the text. The instance from the novels are as follows:

2.1) Amitav Ghosh in his novel The Hungry Tide uses Are moshai an interjection word in Bengali as affective marker to portray a dominating character like Kanai.

Are moshai, can I just say a word? (THT, p. 6)

The character style above portrays Kanai in a very clear as in the beginning of the novel itself he determinedly requests a person to shift from the seat near the window to do his work. This shows how he is capable of getting his place in the world. The author candidly draws the picture how to get the reader to understand this important fact about his main character.

In his other novel Sea of Poppies, Ghosh uses the mix language of the British, which they used when settled in India to get along with the locals. The affective markers are used for depicting habits of a particular community. As one can see in the first example the affective marker is an expletive used by Mr. Doughty an old British sailor, who is residing in India for a long time, addressing the ship's crew in a familiar way which easily marks his character as the no nonsense boss.

Do none of you halalcores any with at all (SOP p. 25)?

Mr Doughty off on a journey of garrulous reminiscence... his tamashers... Sheeshmull blazing with shammers and candles Paltens of bearers and khidmutgars. Demijohns of French loll-shrub and carboys of iced simkin... (SOP p. 47).

In another situation while taking a dinner with the Maharaja of Rashkhali he is shown to be in a merry mood and with his special kind of language like tamashers describes for the audience the past glory of the Rashkhali state. The author with the help of affective markers such as halalcores, shammers etc. make it certain that his character style is plausible and acceptable for the reader.

3) Interlocutory style: In context of literary discourse this style of writing includes the dialogue between the characters and how it helps in the moving forward of the story. As discussed by Pavlenko, "it is in this style that the author engages in what may be called meta-narration, the overtly and explicitly social interactional elements of . . . discourse." (qtd. in Pavlenko, 2006, p. 94).

3.1) In the following example from Ghoss Sea of Poppies the interlocutory style is reinforced with the help of affective markers like an address term, ei beti and the endearing phrase meri jan or my life.

Ei kabutri...ei beti...meri jan! Cradling her daughter in her lap, Deeti kissed

her face until her eyelids began to flicker (SOP p. 194).

In the novel Deeti is going away as a girmitya and has come to see her daughter who she will not meet again. Kabutri, the daughter knows her mother to be dead and is in shock to hear her dead mother talking in the dark. It is a major turning point in the story and Ghosh with interlocutory style and the affective marker is successful in making it clear for the reader. Ghosh does not use any interlocutor style with affective marker in his other novel The Hungry Tide.

4) Mixed style: The discussed styles in the earlier section can be presented alone or concurrently with the other two styles. For example, in indirect discourse, the narrator perspective is combined with that of the quoted character. The three possible combinations of styles are narrator-interlocutory style, character-narrator style and character-interlocutory 
style.

4.1) Amitav Ghosh too uses the mixed style in his novels. There is use of all the possible mixed styles: narratorinterlocutory style, character-narrator style and character-interlocutory style. In The Hungry Tide, there is use of a mixed style in which the author combines the character with the interlocutory style.

Mashima is discussing with Kanai about Fokir and his re-entry into their lives. "I said to her, "Moyna, is this chhele-chhokra your husband then?" and she replied, "Yes, Mashima; this is him" (THT p. 135).

The Bengali expression of chhele-chhokra is the affective marker as it is used as an addressing term for a young man who is not of much consequence and in addition, it is used only for someone who is familiar to the speaker. This produces affect of familiarity and affection for the reader to understand the relations better. The mixed style use in Sea of Poppies facilitate smooth movement of an otherwise complicated novel. The study discusses two of the possible mixed styles in the novel.

So there you are: that's the jadoo of the colonies... No BeeBee so great as to be durwaza-bund when he comes alone...And to seal it all, Miss Catherine Bradshaw for a wife-about as pucka a memsahib as ever there was, brigadier's daughter (SOP p. 77).

In the preceding example, Mr. Doughty relates the life story of Burnham; the informative intention is the mixing of narrator with interlocutory style and the communicative intention is perpetrated by using affective marker jadoo. The marker is describing the situation during colonial times. It was the time when unlike Britain in India there was easy access to success. Burnham, according to Doughty with opportunities available in India became a successful man from a penniless boy. He further describes Burnham's success by retelling his importance as a prospective groom with the affective marker durwaza-bund.

Burnham a boy born on Indian soil and at the time considered as lower in class than the migrated British married a woman of high standing called as pucka memsahib. The second example from the novel is a mixed style formed with character and narrator style wherein the author is using the description style of a narration and writing about an important character like Pauline.

The only voice to be heard was little Annabel's who gave a gleeful shout of laughter: "Mama! She forgot to bundo her jumma! And oh dekko mama, do: there's her ankle! Do you see it? Look what puggly's done” (SOP p. $127-128)$ !

She as an orphan stays with the Burnham household and is addressed as puggly. The character of Pauline is unusual for that age and time as she believes in her own capacity than following the set pattern followed by rest of the "ladies" in colonial India. The affective marker puggly provides the authors informative intention that Pauline is considered as odd and funny when she cannot dress in the proper European way and forgets to button her gown. Pauline being raised by a French father who had hired a Bengali nanny grows up wearing the Bengali apparel for women, the sari. In Pauline's adopted home, the lady of the house Mrs. Burnham was strict about the code of dressing and thus she was nicknamed as puggly.

Drawing analogies between The Hungry Tide and Sea of Poppies while analyzing extracts from the novels, usage of writer styles in addition to affective markers, one can infer how Ghosh portrays various understandings of culture and its performance through language. The analysis of a Diasporic author highlighted the affective stances created by him which increased the performativity through language use and built a cultural identity of characters' voice in the literary text, suggesting that identities are created based on affective performance rather than ritualistic behavior.

\section{Conclusion}

To conclude literary texts like The Hungry Tide and Sea of Poppies follow the rule of literary narrative must satisfy the basic principles of narratives, such as description of human action, and a schematic structure with at least a complication and a resolution within a cultural context. As described, one found that the stories with higher proportions of interlocutory and character style writing were more affectively engaging, relative to stories presented primarily in narrator style. Thus, one can summarize that it is the assumptions of Relevance Theory like informative intention as well as communicative intention and ostensive stimulus which are the devices that instantiate each writer style perspective for a particular affective stance for the reader.

The author writes less as interlocutor and more as a neutral narrator in English than when they are incorporating Hindi (British Hindi) or Bengali with English. Similarly, they generate the voices of quoted characters in more extreme, marked styles in Bengali and Hindi than in English. Talib writes about Ghosh's view where he expresses his concern about English being inadequate to describe the Indian situation (p. 134). This then possibly explains the use of literary multilingualism i.e. affective markers by authors like Ghosh, as they come across as more forceful/intense in Bengali, Hindi than in English. The appropriate conditions of ritualistic speech acts like literature are given in terms of intended attitude change in the reader with respect to the utterance itself ('liking'), whereas effective 'acceptance' of literature again should be sought for outside the pragmatic context, viz in socio-historically and culturally determined systems of norms and values.. Furthermore, this analysis has highlighted the centrally sociolinguistic and cognitive dimensions of 
the relationships between multilingualism and emotion and how this is influenced by assumptions of Relevance Theory i.e. optimal relevance in a literary text. One should expect to find relationships between sociolinguistic diversity and affective expression for most authors in locally specific ways, whether multilingual or not. Hence this discussion facilitated by pragmatic analysis of Amitav Ghosh's two fictions can illuminate how the authors by using literary multilingualism through writer style and affective markers can shape emotions across various contexts within a literary text.

\section{Reference}

Arnold, J. (2011) Attention to affect in language learning. Anglistik: International Journal of English Studies, 22.1: 1122.

Besnier, N. (1990) Language and affect. Annual Review of Anthropology, 19: 419-51. http://www.jstor.org/stable/pdf/2155972.pdf (accessed 12 December 2010).

Crystal, D. (2007) How Language Works. UK: Penguin Publishers. https://books.google.co.in/books?isbn=0141911735 (accessed 12 August 2009).

Ghosh, A. The Hungry Tide. London: HarperCollins, 2004.(THT)

---. Sea of Poppies. New Delhi: Penguin Viking 2008.(SOP)

Haddington, P. , Jarmo H. Jantunen, and Jari Sivonen (2011) Language and affect: go-say and come-say constructions in Finnish. SKY Journal of Linguistics, 24: 75-117.

Kachru, Braj B. (1986) The bilingual's creativity and contact literatures. In Braj B.Kachru (ed.), The Alchemy of English: The Spread, Functions, and Models of Non-native Englishes (pp. 159-73). Oxford: Pergamon Press.

Koven, M. (2006) Feeling in two languages: a comparative analysis of a bilingual's affective displays in French and Portuguese. Bilingual Minds: Emotional Experience, Expression, and Representation. Ed. Aneta Pavlenko (Clevedon, Buffalo, Toronto: Multilingual Matters): 84-117.

Pavlenko, A. , ed. (2006) Bilingual Minds: Emotional Experience, Expression, and Representation (Clevedon, Buffalo, Toronto: Multilingual Matters).

Sperber, D. (1996) Explaining Culture: A Naturalistic Approach (Oxford: Blackwell). http://dx.doi.org/10.1017/S0012217300007149 (accessed 12 October 2010).

Sperber, D. and D. Wilson (1995) Relevance: Communication and Cognition, 2nd Ed. (Oxford: Blackwell).

---. (2002) Relevance theory. Handbook of pragmatics. http://citeseerx.ist.psu.edu/viewdoc/ download?doi=10.1.1.398.9875\&rep=rep1\&type=pdf. (accessed 2 August 2009).

Stevick, W. Earl (1999) Affect in learning and memory: from alchemy to chemistry. Affect in Language Learning. Ed. Jane Arnold. (Cambridge: Cambridge University Press): 43-57.

Talib, Ismail S. (2012) “Ghosh, Language, and The Hungry Tide.” History, Narrative and Testimony in Amitav Ghosh's Fiction. Ed. Chitra Sankaran (Albany: Suny Press): 133-44. 